\title{
LA CONSTITUCIONALIzACIÓN DEL DERECHO EN EL ORDENAMIENTO JURÍDICO COLOMBIANO*
}

\section{THE CONSTITUTIONALIZATION OF THE LAW IN THE COLOMBIAN LEGAL SYSTEM}

\author{
Wilson Yesid Suárez-Manrique** \\ Fecha de recepción: 9 de diciembre de 2013 \\ Fecha de aceptación: 5 de abril de 2014 \\ Disponible en línea: 30 de junio de 2014
}

\section{Para citar este artículo/To cite this article}

\author{
Suárez-Manrique, Wilson Yesid, La constitucionalización del derecho en \\ el ordenamiento jurídico colombiano, 129 Vniversitas, 317-351 (2014). http:// \\ dx.doi.org/10.11144/Javeriana.VJ129.cdoj \\ doi:10.11144/Javeriana.VJ129.cdoj
}

* El presente artículo hace parte de los avances del proyecto de investigación El rol del juez en el Estado Constitucional, presentado a la octava convocatoria interna de la Universidad Santo Tomás, Bucaramanga.

** Doctorando en estado de derecho y gobernanza global, Universidad de Salamanca. Magíster en hermenéutica jurídica y derecho, Universidad Industrial de Santander. Abogado, Universidad Santo Tomás, seccional Bucaramanga. Coordinador especialización en derecho constitucional, Universidad Santo Tomás, Bucaramanga (Colombia). Correo electrónico: wilsonyesidsuarez@gmail.com 


\section{RESUMEN}

El presente escrito, que se sitúa entre los límites de la dogmática y la filosofía del derecho, intenta analizar desde distintas categorías el proceso de constitucionalización judicial, legislativo y académico del ordenamiento jurídico colombiano, y a raíz de ello, propone los rasgos esenciales de un modelo de constitucionalización constructivista como alternativa a los modelos idealista y analítico.

Palabras claves: constitucionalización; nuevos paradigmas; proceso; judicial; construcción 


\section{ABSTRACT}

This paper, which lies between the limits of the dogmatic and philosophy of law, seeks to analyze from different categories the process of judicial, legislative and academic constitutionalization of the Colombian legal system, and as a result, offers the essential features of a model of constructivist constitutionalization as an alternative to the idealistic and analytical models.

Key words: constitutionalization; new paradigms; process; judicial; construction

\section{SUMARIO}

INTRODUCCIÓN.- I. HACIA UNA COMPRENSIÓN DEL PROCESO DE CONSTITUCIOnalización.- $A$. Presupuestos de la constitucionalización del derecho.- 1. Presupuestos de la constitucionalización.- 2. Requisitos del derecho no constitucional.- B. Categorías de análisis del proceso de constitucionalización. - II. LA CONSTITUCIONALIZACIÓN EN EL ORDENAMIENTO JURÍDICO COLOMBIANo.- A. El proceso de constitucionalización colombiano.- B. El proceso de constitucionalización judicial.- C. Constitucionalización legislativa.- D. Constitucionalización práctica y académica.- III. TRES VISIONES ACERCA DE Cómo Se debe Constitucionalizar el Derecho.- $A$. La visión idealista del proceso de constitucionalización.- B. El modelo de constitucionalización adecuado.- C. El proceso de constitucionalización constructivo.- ConCluSIONES.- BIBLIOGRAFÍA. 


\section{INTRODUCCIÓN}

Con posterioridad a la Segunda Guerra Mundial, se ha construido una nueva forma de entender el derecho que parte de la importancia y necesidad de la protección de los derechos fundamentales y la dignidad humana. Este "nuevo constitucionalismo" que puede caracterizarse, entre otras cosas, por la materialización del derecho por medio de los principios constitucionales, la garantía jurisdiccional de la Constitución, la relación del derecho con la moral y la importancia de la argumentación, viene a retar los fundamentos clásicos de la forma como se ha entendido el derecho, en especial mediante el proceso que ha sido llamado constitucionalización del derecho ${ }^{1}$.

Uno de los temas más importantes en las últimas décadas en el ordenamiento jurídico colombiano, y en especial en los ordenamientos jurídicos que han bebido de los proyectos constitucionales europeos de la Segunda Posguerra, es el de "la constitucionalización del derecho" 2 . Las características y la función en el ordenamiento jurídico de esta forma algo novedosa de entender el constitucionalismo ha dado pie a interesantes desarrollos doctrinales y a intricados debates ${ }^{3}$.

1 Hablar del proceso de constitucionalización del derecho resulta un asunto difícil, si no hay un acuerdo sobre nociones generales relacionadas con él. Un diálogo fructífero y dialéctico que desee ser tomado en serio para la comprensión del fenómeno implica un acuerdo mínimo sobre ciertos postulados relacionados con el proceso de constitucionalización. Implica, pues, un acuerdo mínimo, en especial acerca de lo que se entienda por derecho, Constitución, derechos fundamentales y principios. En la doctrina pueden encontrarse nociones disímiles las unas de las otras. Una de las causas de esta situación es que una noción acerca de la constitucionalización del derecho presupone múltiples nociones, que difícilmente suscitan amplio acuerdo entre sí; por ejemplo, presupone las nociones de Constitución, Estado, derecho, función judicial y derechos fundamentales.

2 El proceso de constitucionalización del derecho puede partir de diversos puntos de análisis. Como objeto de estudio puede recibir aportes importantes de la historia, la teoría jurídica, la sociología, la filosofía política y la economía. Tales disciplinas, desde sus perfiles, hacen un aporte importante que nutre la comprensión adecuada del fenómeno.

3 La falta de consenso más o menos claro da lugar, entre otras cosas, a posiciones a favor y en contra del proceso de constitucionalización del derecho. Desde la economía, se han recibido grandes críticas a este proceso, en especial con el argumento de los aspectos ineficientes a que lleva el derecho constitucionalizado. La sociología, por su parte, ha entendido el proceso como ineficaz. Pues el gran catálogo de promesas difícilmente puede ser cumplido. La filosofía moral ha visto el proceso como un lugar propicio para la institucionalización de sus debates. Desde las concepciones clásicas del derecho privado, se entiende que se afrentan sus presupuestos básicos. Cfr. MaUricio García-VIllegas, Notas preliminares para la caracterización del derecho en América Latina, 26 Revista El Otro Derecho, 13-49 (2003). Disponible en: http://www.oas. org/juridico/spanish/mauricio_garc\%C3\%ADa_villegas.htm 
La finalidad del presente escrito es la de mostrar algunas categorías que permitan comprender de forma adecuada el proceso de constitucionalización del derecho en el ordenamiento jurídico colombiano y cómo se puede llegar a que ese proceso se desarrolle de forma óptima. Para cumplir esta finalidad, el presente escrito se divide en tres partes generales. La primera, de carácter analítico, está dedicada al establecimiento de algunas categorías que permiten el análisis del proceso de Constitucionalización de una forma holística, para que se puedan vislumbrar los rasgos más importantes de este proceso. En la segunda parte, se toman estas categorías para describir por medio de ellas cuál ha sido el proceso de constitucionalización del derecho en el ordenamiento jurídico colombiano. En la tercera parte, en forma prescriptiva, se desea demostrar cuál sería la forma más apropiada para llegar a un proceso de constitucionalización óptimo, que se presente como una alternativa respecto al idealismo y al excesivo formalismo.

\section{HACIA UNA COMPRENSIÓN DEL PROCESO DE CONSTITUCIONALIZACIÓN}

Como se anticipó, esta parte está dedicada al establecimiento de algunas categorías que permiten el análisis del proceso de constitucionalización de una forma holística, para que se puedan vislumbrar los rasgos más importantes de la constitucionalización. Para ello, este aparte se divide en dos secciones. En la primera se refieren los presupuestos de la constitucionalización y en la segunda, las categorías de análisis.

\section{A. Presupuestos de la constitucionalización del derecho}

Para hablar en términos generales de la constitucionalización del derecho, se necesitan ciertos presupuestos mínimos sin los cuales este fenómeno no tiene cabida. Entre los diferentes presupuestos mínimos, unos se refieren a la Constitución y otros al derecho que se pretende constitucionalizar. El análisis de los presupuestos de constitucionalización, de forma directa o de forma subrepticia, ha hecho hincapié en los factores que giran en torno a la Constitución 
y no al objeto de la constitucionalización, es decir, el acento está en el elemento "dominante" y pasa por alto los elementos "dominados", lo cual ha llevado a una revisión unidireccional del fenómeno.

\section{Presupuestos de la constitucionalización}

Hay ciertos elementos del derecho constitucional sin los cuales no puede pensarse que se dé el fenómeno de la Constitucionalización: contenido material e indeterminado, fuerza vinculante, máxima jerarquía y garantía de la Constitución ${ }^{4}$.

Una Constitución tiene contenido material cuando está dotada de principios y reglas jurídicas, mediante los cuales se establece que ciertas conductas están ordenadas, prohibidas o permitidas. Lo importante desde esta perspectiva es que la Constitución no sea simplemente un catálogo de buenas intenciones para desarrollar en un futuro, sino que de sus disposiciones de derecho fundamental puedan extraerse normas directamente estatuidas, adscritas o individuales, por medio de las cuales las conductas del Estado y los particulares estén condicionadas ${ }^{5}$. Así mismo, se hace necesario que algunos de los postulados constitucionales con contenido material tengan fuerza normativa. Es decir, sean obligatorios para sus destinatarios. Ello representa el paso de concebir la Constitución como una idea a considerarla como una norma.

El contenido material de la Constitución ha de ser indeterminado. La indeterminación del contenido, antes que verse como una situación indeseable, es una situación que puede valorarse positivamente $^{6}$. Ello permite desarrollar los derechos fundamentales y sus postulados en diferentes grados. Lo que facilita, en otras palabras, entender la constitucionalización del derecho desde un contenido

4 Estas características se pueden inferir de los siguientes textos: Robert Alexy, Teoría de los derechos fundamentales, 503-553, Centro de Estudios Políticos y Constitucionales, CEPC, Madrid (1993). CARlos Bernal, El neoconstitucionalismo y la normatividad en el derecho, 8393, Universidad Externado de Colombia, Bogotá (2009).

5 En general, podría decirse en este sentido: "Los derechos fundamentales se conciben en una doble cualificación de los derechos fundamentales. Se conciben, por un lado, como derechos subjetivos de libertad, que hacen parte de la esfera jurídica de su titular individual y, por otra parte - y al mismo tiempo-, como las objetivas de principio (objektive Grundsatznormen) y decisiones lógicas (Wertentscheidungen) que tienen valor para todos los ámbitos del derecho. Alexei Julio-Estrada, La eficacia de los derechos fundamentales entre particulares, 66, Universidad Externado de Colombia, Bogotá (2002).

6 Carlos Bernal, El neoconstitucionalismo y la normatividad en el derecho, 19-42, Universidad Externado de Colombia, Bogotá (2009). 
abstracto y prima facie. Estas normas se caracterizan por que son mandatos de optimización, es decir, su contenido debe ser cumplido en la mayor medida posible dentro de las posibilidades fácticas y jurídicas ${ }^{7}$. Ello, de contera, implica que los principios tienen diferentes contenidos y que pueden cumplirse en distintos grados.

La máxima validez jerárquica, como requisito para hablar de la constitucionalización del derecho, significa que no haya una norma jurídica superior a la Constitución. Es decir, ella es el máximo vértice jurídico en el ordenamiento jurídico, por lo cual, las demás disposiciones jurídicas deben subordinarse a ella ${ }^{8}$. Así pues, el derecho legislado y los actos de los particulares deben respetar los límites materiales y formales de la Constitución.

La garantía de la Constitución implica, por su parte, que debe haber órganos y procedimientos que pretendan hacer valer la supremacía de la Constitución. En el ordenamiento jurídico, diferentes actores están encargados de la tarea de velar por la supremacía constitucional. Bien sea de forma directa o indirecta, mediante acciones de tutela o amparo, o acciones de inconstitucionalidad o de revisión constitucional, bien se trate de controles difusos, concertados, especializados o generales, lo importante es que se hayan establecido procedimientos y órganos para respetar las posibles infracciones al contenido constitucional.

\section{Requisitos del derecho no constitucional}

Para que los ámbitos distintos al derecho constitucional puedan ser constitucionalizados, se necesita que cumplan tres requisitos generales: no definidos enteramente, susceptibles del cambio y con poca influencia de la constitución actual.

7 Robert Alexy, Teoría de los derechos fundamentales, 86, Centro de Estudios Políticos y Constitucionales, CEPC, Madrid (1993).

8 Como estrategia para solucionar el problema del alcance de la legalidad, Luigi Ferrajoli presenta una forma de ver el Estado de Derecho, desde la perspectiva sentada por los estados constitucionales, en la cual convergen, como forma de legitimación, la mera legalidad y la estricta legalidad. Para Ferrajoli: En todos los casos se puede decir que la mera legalidad, al limitarse a subordinar todos los actos a la ley cualquiera que sea, coincide con su legitimación formal, mientras la estricta legalidad, al subordinar todos los actos, incluidas las leyes, a los contenidos de los derechos fundamentales, coincide con su legitimación sustancial. Luigi Ferrajoli, Derecho y razón, 857, Trotta, Madrid (2001). 
Un ámbito de derecho no definido enteramente significa que hay cosas por decir en su campo de regulación ${ }^{9}$. Una esfera jurídica en la cual ya se ha dicho todo acerca de las conductas que se regulan no tendría posibilidades reales de ser constitucionalizada. Un ámbito no definido enteramente significa que no se tiene claridad en todos los casos acerca de lo que debe resolver el juez, hay vacíos, contradicciones, ambigüedades, indeterminaciones; es un derecho que puede ser completado e integrado por el derecho constitucional. Es decir, hay elementos de decisión y discrecionalidad en los cuales los parámetros constitucionales pueden ayudar a solucionar y crear problemas. Se trata pues, de un derecho que permite la entrada en regencia del derecho constitucional de diferentes formas. Bien sea para la aplicación del derecho a los casos no regulados, la regulación conforme en los casos indeterminados o una regulación preferente en contra del derecho legislado.

Además del anterior requisito se hace necesario que el ámbito de derecho no constitucional admita el cambio, es decir, que pueda ser moldeado por el derecho constitucional; si la esfera a ser constitucionalizada no admite la moderación por parte del derecho constitucional, no podría darse el fenómeno. Este requisito quizás puede entenderse implícito en la máxima validez jerárquica de la Constitución.

En tercer lugar: para hablar de que el derecho se está constitucionalizando se hace necesario que tal o cual ámbito, en principio, tenga poca similitud con los contenidos de la Constitución. Entre menos tenga en cuenta el derecho los postulados del derecho constitucional más susceptible es de ser constitucionalizado. Desde cierta perspectiva, la constitucionalización del derecho parte de un derecho no constitucionalizado con la Constitución vigente.

\section{B. Categorias de análisis del proceso de constitucionalización}

La primera aclaración que desea efectuarse en este aparte es que la constitucionalización del derecho se entiende como un proceso. Este proceso puede ser estudiado desde una perspectiva descrip-

9 Cfr. Carlos Bernal, El neoconstitucionalismo a debate, 12-25, Universidad Externado de Colombia, Bogotá (2006). 
tiva o prescriptiva. Y puede tener como vehículos de desarrollo la legislación, las sentencias judiciales, la conducta de los juristas y los desarrollos académicos. Estas distintas formas de constitucionalización llevan, entre otras cosas, a que sea un proceso sectorial.

Que la constitucionalización se entienda como un proceso significa el establecimiento de características muy interesantes: es dinámico, tiene puntos de partida y llegada, no es unidireccional y puede ser contradictorio. La constitucionalización se muestra como una entidad dinámica en contraposición a una entidad estática; no puede decirse simplemente que un ordenamiento jurídico está o no constitucionalizado, un ordenamiento jurídico puede constitucionalizarse en diferentes grados ${ }^{10}$. De hecho, en los ordenamientos jurídicos que se han estado constitucionalizando puede notarse que el proceso de avance ha sido en diversos grados y con distintas características. Los puntos de partida y de llegada del ordenamiento que se constitucionalizan no son los mismos, pueden darse casos en los cuales se parte de ordenamientos jurídicos más constitucionalizados que otros, y casos en los cuales el ordenamiento está menos constitucionalizado que en otros. Difícilmente, se puede decir que dos ordenamientos jurídicos que se constitucionalizan arranquen y finalicen en el mismo punto.

Desde esta óptica, puede comprenderse que la afirmación de que un ordenamiento jurídico está o no constitucionalizado no es del todo precisa. Tal afirmación debe complementarse con la calificación del grado, bien sea mediante una escala cualitativa o cuantitativa. No obstante, no se puede pedir precisión geométrica.

Además de ello, hay que entender que como proceso, la constitucionalización del derecho puede avanzar y retroceder; y que su avance y su retroceso son distintos en los diferentes ámbitos. Así pues, se entiende que el proceso de constitucionalización en un

10 Paolo Comanducci, retomando la tripartición efectuada por Norberto Bobbio en el Problema del positivismo jurídico, habla de un neoconstitucionalismo teórico, ideológico y metodológico. El primero, el teórico, hace alusión a la descripción del proceso de constitucionalización del derecho. El segundo, el ideológico, "valora positivamente (los cambios señalados por el teórico) y propugna su defensa y ampliación". "El neoconstitucionalismo metodológico sostiene la tesis de la conexión necesaria, identificativa o justificativa, entre derecho y moral". Paolo Comanducci, Formas de (neo)constitucionalismo: un análisis metateórico, 16 Isonomía, 89-112 (2002). Disponible en: http://www.upf.edu/filosofiadeldret/_pdf/comanducci-formas. pdf. Miguel Carbonell, Teoría del neoconstitucionalismo, ensayos escogidos, 41, Trotta, Universidad Nacional Autónoma de México, UNAM, Instituto de Investigaciones Jurídicas, Madrid (2007). 
futuro implique su retroceso, una vuelta al legalismo, o que en el ámbito comercial los efectos de la constitucionalización del derecho implique el retroceso actual, por lo incompatible del proceso con la naturaleza de ese ámbito y la necesaria libertad y estabilidad requerida.

Este proceso de constitucionalización puede revisarse desde una perspectiva descriptiva o prescriptiva ${ }^{11}$. Desde una perspectiva descriptiva, se trata de decir, simplemente, cómo se ha dado el proceso, de dar cuenta de una realidad jurídica tal como se cree que ha venido sucediendo. En cambio, desde una perspectiva prescriptiva, se trata de decir cómo debe ser el proceso de constitucionalización del derecho; el asunto no se agota o no se enfrasca en decir cómo se ha dado el proceso, sino cómo se debería dar el proceso y cuál es la mejor forma de constitucionalizar el ordenamiento jurídico. Mientras que la primera pregunta sería ¿cómo se ha dado el proceso de constitucionalización del derecho?, la segunda pregunta sería ¿cómo debe darse el proceso de constitucionalización del derecho?

El proceso de constitucionalización en clave descriptiva ha tenido dos vehículos principales para el desarrollo. Se ha dado el caso de ordenamientos jurídicos constitucionalizados preferentemente por vía legislativa y otros constitucionalizados preferentemente por vía judicial ${ }^{12}$. Los vehículos más importantes por los cuales se han constitucionalizado los ordenamientos jurídicos son el judicial o el legislativo ${ }^{13}$. Empero, ello no implica que sean los únicos mecanismos para constitucionalizar el ordenamiento jurídico, pues pueden ser utilizados otros vehículos para constitucionalizar el derecho, así pues, puede hablarse de una constitucionalización vía

11 Eduardo Melero-Alonso, La dogmática jurídica es política. La importancia de las concepciones políticas en el trabajo de los juristas: un acercamiento desde el derecho público, 36, Universidad Autónoma de Madrid, Madrid (2002). Disponible en: http://www.uam.es/personal_pdi/derecho/jarsey/3publicaciones/dogmaticaespolitica.pdf. Aunque en algunas ocasiones, incluso, tal aspecto, el de la validez, puede ser estudiado. Manuel Atienza, El futuro de la dogmática jurídica, crítica de libros, 10 El Basilisco, 63-69 (1980). Disponible en: http://www.fgbueno.es/ bas/pdf/bas11008.pdf. CARlos Alchourrón \& Eugenio Bulygin, Introducción a la metodología de las ciencias jurídicas y sociales, 21, Editorial Astrea, Buenos Aires (1974). Disponible en: http://www.cervantesvirtual.com/nd/ark:/59851/bmczc7x4

12 Mauricio García-Villegas, Constitucionalismo aspiracional: Derecho, democracia y cambio social en América Latina, 25 Análisis Político, 75, 89-110 (mayo-agosto, 2012). Disponible en: http://www.scielo.org.co/scielo.php?script=sci_arttext\&pid=S0121-47052012000200005

13 Ejemplo del ordenamiento constitucionalizado preferentemente por vía judicial es el del caso colombiano, y ejemplo del constitucionalizado por vía legislativa puede ser Venezuela. 
académica o vía práctica ${ }^{14}$. Se trata de una constitucionalización vía académica cuando el proceso tiene como vehículo la enseñanza del derecho, la forma como se estudia, los desarrollos teóricos, los congresos, seminarios, libros y artículos publicados sobre el tema. Por su parte, la constitucionalización se da desde una perspectiva práctica cuando la constitucionalización es utilizada desde el punto de vista del abogado litigante; cuando en los litigios se plantean argumentos de orbe constitucional bien sea como fundamento de las pretensiones o por vía de excepción.

A su vez, no hay que perder de vista que el proceso de constitucionalización del derecho es sectorial. Quiere decirse con esto que no todas las partes del ordenamiento jurídico se constitucionalizan de la misma manera. Hay partes del ordenamiento jurídico que pueden constitucionalizarse más que otras ${ }^{15}$, pues hay campos más susceptibles a la influencia de los contendidos del derecho constitucional. En cambio, hay ámbitos que parecen no ser muy cercanos al proceso de constitucionalización por la escasa posibilidad de que se entre en debates de tipo constitucional ${ }^{16}$.

\section{LA CONSTITUCIONALIZACIÓN EN EL ORDENAMIENTO JURÍDICO COLOMBIANO}

En este acápite se retoman las categorías referidas en el numeral anterior y se aplican en el proceso de constitucionalización en el ordenamiento jurídico colombiano. Se muestra cómo la constitu-

14 En este punto, se utiliza la expresión práctica en un sentido impropio. No quiere negarse que otras actividades distintas a la del abogado litigante sean prácticas.

15 Por ejemplo, Juan Jacobo Calderón, en La constitucionalización del derecho privado, analiza como casos paradigmáticos los contratos de seguro, los contratos bancarios y los de medicina prepagada. JUAN JACOBO CALDERÓN-VILLEGAS, La constitucionalización del derecho privado. La verdadera historia del impacto constitucional en Colombia, Uniandes, Bogotá (2011).

16 Además de estas categorías, hay que ver que la constitucionalización del derecho conlleva dos visiones distintas: la del constitucionalista y la del civilista. La perspectiva del constitucionalista es la de quien trabajó en esta área del derecho y ahora ve con regocijo que su objeto de estudio se amplía y entra a condicionar las otras esferas del derecho, bien se trate del derecho penal, civil, laboral o administrativo. Esta perspectiva es de carácter progresista, el ángulo de quien la hace es el de querer ampliar su poder de decisión. En contraposición de esta postura está la del privatista que ve en el derecho constitucional un criterio alterno para la solución de los problemas que se presentan en su campo. Es una perspectiva conservadora, no tiene la intención de modificar de tajo y de forma importante la clásica concepción del derecho sobre la que se ha soportado; de forma tímida, solo quiere ver en el derecho constitucional un auxilio. 
cionalización ha sido un proceso creciente que, a partir de la Constitución de 1991, se ha venido desenvolviendo en manera siempre amplificada. En un principio tuvo como principal protagonista a la Corte Constitucional ${ }^{17}$. No obstante, de forma posterior, las demás altas ramas judiciales poco a poco han entrado en sintonía de esa nueva forma de entender el derecho; así mismo, el legislador, la academia y los litigantes han entrado en esta nueva manera de entender el derecho y las relaciones jurídicas. Este proceso de constitucionalización ha estado concentrado en ciertas áreas del derecho, en especial en aquellas en las que es clara la situación de superioridad de una parte respecto de la otra.

\section{A. El proceso de constitucionalización colombiano}

El proceso de constitucionalización del ordenamiento jurídico colombiano puede calificarse como lento, dispar, con diferentes puntos de entronque, preferiblemente judicial y que hacia el futuro presenta interesantes interrogantes.

El proceso de constitucionalización del ordenamiento jurídico inició con la Constitución de 1991. Con la expedición de este texto jurídico se dio un viro respecto a la forma de ver el derecho que se traía desde la Constitución de 1886; podría calificarse de una revuelta en contra del formalismo ${ }^{18}$.

La concepción fuerte de la nueva Constitución ${ }^{19} \mathrm{y}$, en especial, de los derechos fundamentales, mediante la cual estos revelan la potestad de irradiar el ordenamiento jurídico y condicionar situaciones que otrora regulaba la ley o estaban sometidas al arbitrio de los privados, comenzó a surgir en el ordenamiento jurídico interno a partir de la Carta de $1991^{20}$. Así pues, "los textos Constituciona-

17 Diego López-Medina, Teoría impura del derecho. La transformación de la cultura jurídica latinoamericana, 345-391, Legis, Universidad de los Andes, Universidad Nacional, Bogotá (2004).

18 Diego López-Medina, Interpretación constitucional, Universidad Nacional de Colombia, Bogotá, 5-6 (2006).

19 La Constitución de 1886 era portadora de una concepción débil de Derechos fundamentales. Es más, no consagraba como tales Derechos fundamentales. En el título III de la Constitución se establecía "De los Derechos civiles y garantías sociales", entre los cuales se situaban algunas de las libertades que hoy se consideran Derechos fundamentales. Colombia, Constitución Politica de la República de Colombia (1886). Disponible en: http://www.alcaldiabogota.gov. co/sisjur/normas/Norma1.jsp?i=7153

20 Los principales cambios en el Derecho positivo se evidencian en el aparecimiento de Constitu- 
les, y muy en particular aquellos en los que se consagran derechos fundamentales de las personas, se han convertido en principios y reglas directamente aplicables a todo tipo de conflictos jurídicos a resolver por los jueces y funcionarios administrativos en Colombia".

"Esta especial caracterización de los derechos fundamentales se encuentra expresada, principalmente, en los artículos 4, 5 y 86 del texto colombiano"21. La supremacía de la Constitución da prevalencia a los derechos fundamentales, la existencia de inalienabilidad de los derechos les otorga un plus de permanencia, y la presencia de un mecanismo expedito para hacerlos valer les da una trascendental garantía. Es decir, la Constitución es concebida como norma de normas y se resalta así el hecho de su superioridad sobre las demás disposiciones del ordenamiento jurídico, pues se la dota además de un carácter normativo, mediante el cual puede ser aplicada en alguno de sus apartes, de forma directa por los jueces sin necesidad de desarrollo legal. La primacía de los derechos inalienables de las personas otorga un estatus trascendente a la concepción de persona

ciones garantistas y con fuerza normativa. En Europa resaltan los textos constitucionales de Italia (1947), Alemania (1949), Portugal (1976) y España (1978). En Latinoamérica, sobresalen los textos de Brasil (1988), Colombia (1991), Panamá (1972), Perú (1993), Argentina (1994), Bolivia (1995, 2009), Ecuador (1998), Venezuela (1999). Italia, Constituzione della Repubblica Italiana (1947). Texto en italiano: http://www.governo.it/Governo/Costituzione/principi.html, texto en español: http://www.italianoinfamiglia.it/documenti/costituzione-in-spagnolo.pdf. Alemania, Grundgesetz für die Bundesrepublik Deutschland (1949). Texto en alemán: http:// www.gesetze-im-internet.de/gg/BJNR000010949.html, texto en español: http://ocw.um.es/ cc.-juridicas/derecho-internacional-publico-1/ejercicios-proyectos-y-casos-1/capitulo4/ documento-20-constitucion-de-alemania.pdf. Portugal, Constitução da República Portuguesa (1976). Texto en portugués: http://www.parlamento.pt/legislacao/paginas/constituicaorepublicaportuguesa.aspx, texto en español: http://www.viajeuniversal.com/portugal/constitucion1. htm, http://www.viajeuniversal.com/portugal/constitucion2.htm. España, Constitución Española (1978). Disponible en: http://www.congreso.es/consti/constitucion/indice/. Brasil, Constituição da República Federativa do Brasil (1988). Texto en portugués: http://www. planalto.gov.br/ccivil_03/constituicao/constituicao.htm, texto en español: http://www.wipo. int/wipolex/es/text.jsp?file_id=218272. Colombia, Constitución Politica (1991). Disponible en: http://www.alcaldiabogota.gov.co/sisjur/normas/Norma1.jsp?i=4125. Panamá, Constitución Politica de la República de Panamá (1972). Disponible en: http://www.asamblea.gob.pa/main/ LinkClick.aspx?fileticket=fDgmRvYW8cY\%3D\&tabid=123. Perú, Constitución Politica del Perú (1993). Disponible en: http://www.tc.gob.pe/constitucion.pdf. Argentina, Constitución Nacional (1994). Disponible en: http://www.senado.gov.ar/deInteres. Bolivia, Constitución Politica del Estado (1995). Disponible en: http://www.lexivox.org/norms/BO-CPE-19950206. xhtml. Bolivia, Constitución Política del Estado (2009). Disponible en: http://bolivia.infoleyes. com/shownorm.php?id=469. Ecuador, Constitución Política de la República del Ecuador (1998). Disponible en: http://www.ecuanex.net.ec/constitucion/indice.html. Venezuela, Constitución de la República Bolivariana de Venezuela (1999). Disponible en: http://www.tsj.gov.ve/legislacion/ constitucion 1999.htm

21 Diego López-Medina, Interpretación constitucional, Universidad Nacional de Colombia, Bogotá, 5-6 (2006). 
y sus derechos fundamentales, los cuales se conciben con fundamento en la dignidad humana. La acción de tutela es un mecanismo expedito y sumario que las personas ostentan para acudir al juez ordinario para reclamar de manera directa, ya no por intermedio de la ley, la protección a sus derechos fundamentales dados por la Constitución.

Hoy, más de veintitrés años después, el proceso de constitucionalización está en formación, tratando de adaptarse. Ha sido un proceso lento pues más de dos décadas después de la entrada en vigencia de la Constitución todavía se debate acerca de la existencia, el alcance y la utilidad del proceso. No puede decirse que actualmente se tenga una noción clara y ampliamente aceptada de lo que significa el proceso y sus características ${ }^{22}$.

Tal vez la lentitud del proceso en sus inicios se debió especialmente a su disparidad. Tenía como principal cabeza visible a la Corte Constitucional. Difícilmente, se veía el aporte de las demás altas Cortes y del legislador en el proceso. La Corte Suprema de Justicia, el Consejo de Estado y el legislador, como se indica más adelante, solo una década después empezaron a acompasarse con esta nueva forma de entender el derecho.

El futuro del proceso de constitucionalización puede verse desde una perspectiva optimista o escéptica, bien sea que se logre una materialización del derecho más o menos óptima, o que se abandone ante la incoherencia e inestabilidad que genere. "La tarea de discurrir sobre lo que vendrá no es sencilla, en ningún tiempo, y menos en los que vivimos; tiempo jurídico de transición, de un derecho flexible y volátil, al decir de José Luis de los Mozos"23. Como todo proceso en el derecho, su materialización también es cíclica. El derecho continuará materializándose hasta llegar a un punto de extrema inestabilidad en el cual tendrá que retroceder. De

22 Distintos sectores de la academia y la práctica aún debaten la existencia del proceso.

23 "Tres juristas franceses, de muy fina sensibilidad, han sido los anticipadores del actual estado de cosas y, en buena medida, del Derecho por venir. Nos referimos a [Georges] Ripert, que a partir de 1920 fue señalando, aunque con escepticismo, el rostro 冈del derecho privado de la democracia $\bigotimes$, en el cual veía la $\bigotimes$ declinación del Derecho囚. Otro realista moderado, aunque optimista y marcadamente evolucionista, fue René Savatier, que a mediados del siglo, 1950 nos habló de la đmetamorfosis económica y social del derecho civil囚 y de cómo se iba produciendo la đinvasión del derecho privado por el derecho público囚. Y, por último, [Jean] Carbonnier, que a partir de 1950 destaca la necesidad, para el jurista, de conocer la realidad y se rehúsa a hablar de una \contaminación del Derecho Privado囚”. Ricardo Lorenzetti, Tratado de los contratos, parte general, Rubinzal-Culzoni, Buenos Aires, 454-458 (2004). 
manera irremediable, la materialización del derecho tendrá que caer nuevamente en el formalismo. La idea de la teoría y la dogmática será pues hacer más duradero el proceso.

\section{B. El proceso de constitucionalización judicial}

\section{La constitucionalización del derecho en el ordenamiento jurídico} colombiano ha tenido como principal actor a la Corte Constitucional $^{24}$. Ella ha actuado como principal factor de cambio, defendido y expandido los contenidos de la Constitución en diversas líneas.

Estas tareas desarrolladas por la Corte Constitucional se han efectuado especialmente en dos líneas diferentes: bien sea actuando en sus competencias de control de constitucionalidad de las leyes ${ }^{25}$ o por vía de revisión de tutela ${ }^{26}$. En el primer supuesto la Corte, según sea el caso, revisa que los condicionamientos materiales y procesales de la ley se ajusten a los postulados de la Carta; es una garantía jurisdiccional en aras a salvaguardar la supremacía de la Constitución. Se trata de efectuar un control procesal y material en la expedición de las normas. En este sentido, los modelos argumentativos que utiliza la Corte - como el principio de proporcionalidad $^{27}$, el test de razonabilidad o el de igualdad ${ }^{28}$ - ocupan un lugar central en su doctrina. Como premisas para el control de constitucionalidad, la Corte se ha encargado de efectuar construcciones semánticas acerca del contenido y el alcance de los derechos

24 Diego López-Medina, Teoría impura del derecho. La transformación de la cultura jurídica latinoamericana, Legis, Universidad de los Andes, Universidad Nacional, Bogotá, capítulo 5 (2004).

25 Y demás funciones de salvaguarda de la supremacía de la Constitución, de conformidad con el artículo 241 de la Constitución Política.

26 Los fallos de tutela en primera o segunda instancia se enviarán a la Corte Constitucional para su eventual revisión. Colombia, Decreto 2591 de 1991, por el cual se reglamenta la acción de tutela consagrada en el artículo 86 de la Constitución Politica, 40.165 Diario Oficial (19 de noviembre de 1991). Disponible en: http://www.alcaldiabogota.gov.co/sisjur/normas/Norma1. jsp?i=5304

27 Corte Constitucional, Sentencia T-301 de 2004, 25 de marzo de 2004. Magistrado ponente Eduardo Montealegre-Lynett. Disponible en: http://www.corteconstitucional.gov.co/ relatoria/2004/t-301-04.htm. Corte Constitucional, Sentencia C-093 de 2001, 31 de enero de 2001. Magistrado ponente Alejandro Martínez-Caballero. Disponible en: http://www.corteconstitucional.gov.co/relatoria/1999/C-582-99.htm

28 Corte Constitucional, Sentencia T-555 de 2011, 8 de junio de 2011. Magistrado ponente Nilson Pinilla-Pinilla. Disponible en: http://www.corteconstitucional.gov.co/relatoria/2011/T-555-11. $\mathrm{htm}$. Corte Constitucional, Sentencia T-340 de 2010, 11 de mayo de 2010. Magistrado ponente Juan Carlos Henao-Pérez. Disponible en: http://www.corteconstitucional.gov.co/ relatoria/2010/T-340-10.htm 
fundamentales y los principios constitucionales, como primer paso para efectuar la posterior comparación semántica entre los enunciados. El establecimiento de esta clase de premisas ha sido una excusa perfecta para la construcción de la doctrina constitucional.

Por su parte, en el campo de la revisión de tutelas, la Corte ha dado algunos de los pasos más importantes del proceso de constitucionalización. Ello se vislumbra principalmente en el paso del control abstracto a la resolución de problemas concretos. En este escenario, la Corte ha hecho una reconstrucción de los alcances y el sentido de los derechos fundamentales en circunstancias puntuales; de cierta forma, ha sobreinterpretado la Constitución, para pasar de una concepción con alto grado de abstracción a su acercamiento concreto.

Mediante estas dos líneas generales de trabajo, la Corte ha realizado tres actividades dignas de resaltar: en primer lugar, ha reconstruido lo que puede denominarse como derechos innominados ${ }^{29}$; en segundo lugar, ha hecho una ampliación real de los contenidos de la Constitución mediante la figura del bloque de constitucionalidad $^{30} ; \mathrm{y}$, en tercer lugar, un elemento importante de la eficacia del proceso, ha tratado de hacer obligatorias sus decisiones mediante diferentes mecanismos: como el precedente ${ }^{31}$ y las consecuencias de su inaplicación, la interpretación por autoridad ${ }^{32}$ y las sentencias inter pares e inter comunis ${ }^{33}$.

29 Corte Constitucional, Sentencia T-406 de 1992, 5 de junio de 1992. Magistrado ponente Ciro Angarita-Barón. Disponible en: http://www.corteconstitucional.gov.co/relatoria/1992/t-406-92. htm. Corte Constitucional, Sentencia T-881 de 2002, 17 de octubre de 2002. Magistrado ponente Eduardo Montealegre-Lynett. Disponible en: http://www.corteconstitucional.gov.co/ relatoria/2002/t-881-02.htm. Corte Constitucional, Sentencia T-719 de 2003, 20 de agosto de 2003. Magistrado ponente Manuel José Cepeda-Espinosa. Disponible en: http://www.corteconstitucional.gov.co/relatoria/2003/T-719-03.htm

30 Corte Constitucional, Sentencia C-225 de 1995, 18 de mayo de 1995. Magistrado ponente Alejandro Martínez-Caballero. Disponible en: http://www.corteconstitucional.gov.co/ relatoria/1995/c-225-95.htm. Corte Constitucional, Sentencia C-582 de 1999, 11 de agosto de 1999. Magistrado ponente Alejandro Martínez-Caballero. Disponible en: http://www. corteconstitucional.gov.co/relatoria/1999/C-582-99.htm

31 Corte Constitucional, Sentencia C-037 de 1996, 5 de febrero de 1996. Magistrado ponente Vladimiro Naranjo-Mesa. http://www.corteconstitucional.gov.co/relatoria/1996/C-037-96. htm

32 Corte Constitucional, Sentencia C-820 de 2006, 4 de octubre de 2006. Magistrado ponente Marco Monroy-Cabra. Disponible en: http://www.corteconstitucional.gov.co/ relatoria/2006/C-826-06.htm

33 Corte Constitucional de Colombia. Auto-071 de 2001, 27 de febrero de 2001. Magistrado ponente Manuel José Cepeda-Espinosa. Disponible en: http://www.corteconstitucional.gov. co/relatoria/autos/2001/a071-01.htm 
Con el transcurso del tiempo, esta tarea desarrollada por la Corte Constitucional ha venido contando con la adhesión de las demás altas Cortes. Estas corporaciones, al principio reacias a iniciar continuar - con el proyecto, poco a poco se han venido acercando a la nueva configuración del Derecho y les han dado peso a los principios y argumentos constitucionales en sus decisiones. Ello no implica, claro está, que se hayan desapegado completamente de la ley; simplemente están coadyuvando dentro del proceso.

Así, por ejemplo, resulta significativo lo establecido por la Corte Suprema de Justica ${ }^{34}$ en sentencia del 1 de agosto de 2007:

El Contrato Social colombiano, en el que se consagra un Estado Social de Derecho, gobernado por valores, principios superiores, derechos fundamentales y deberes, destina con la mayor fuerza vinculante al proceso penal los preceptos referidos a la legalidad, el debido proceso y el derecho de defensa.

En similar sentido, el Consejo de Estado, en sentencia del 13 de abril de $2011^{35}$, preceptuó:

Con la Carta Política de 1991 se produjo la \constitucionalización $₫$ de la responsabilidad del Estado y se erigió como garantía de los derechos e intereses de los administrados, sin distinguir su condición, situación e interés.

El hecho de que la Corte Suprema de Justicia y el Consejo de Estado no hayan participado del mismo modo en el proceso de constitucionalización del derecho, obedece a tres razones principales: la tradición, la estabilidad y la subsidiariedad. En primer lugar, estas corporaciones por tradición han venido resolviendo sus litigios con estricto apego a las nociones legales, salvo el período de los años treinta. En segundo lugar, en los campos jurídicos privado y administrativo, la relativa estabilidad de las normas jurídicas es un presupuesto inexorable para la creación y modificación de relaciones. En tercer lugar, la influencia del derecho constitucional en estas áreas se ha visto más como una forma de llenar lagunas o

34 Corte Suprema de Justicia, Sala de Casación Penal, Sentencia del 1 de agosto de 2007. Proceso 27283. Magistrado ponente Yesid Ramírez-Bastidas. Disponible en: http://beneficiosjudiciales. blogspot.com/2007/11/defensa-tecnica.html

35 Consejo de Estado, Sala de lo Contencioso Administrativo, Sección Tercera, Sentencia del 13 de abril de 2011. Proceso 20480. Consejero ponente Jaime Orlando Santofimio-Gamboa. Disponible en: http://www.alcaldiabogota.gov.co/sisjur/normas/Norma1.jsp?i=46494 
solucionar problemas interpretativos que como una fuente directa. En cambio, por la naturaleza, objeto y misión de la Corte Constitucional se entiende su participación activa; los papeles han sido contextualizados.

En los párrafos anteriores se manifestó que el proceso de constitucionalización del derecho liderado por la Corte Constitucional ha contado con una participación regular de las demás Altas Cortes; además de ello, puede afirmarse que el proceso disminuye cuando disminuye la jerarquía del juez. La Corte Suprema de Justicia y el Consejo de Estado han venido cediendo, y tal vez retomando, la concepción antiformalista del derecho, según la cual no solo el derecho legislado es fuente del derecho. No obstante, la consideración del proceso de constitucionalización directo por parte de los jueces de inferior jerarquía es un fenómeno poco visto; la mayoría de las ocasiones se efectúa más por el seguimiento de los precedentes de las Altas Cortes que por un análisis de los argumentos constitucionales.

Esta hipótesis puede deberse a cinco argumentos principales ${ }^{36}$. El primero dice que los jueces de las instancias menores están más apegados a las concepciones del legalismo que han dominado las formas de resolver los conflictos desde antaño. El segundo, que esta forma de resolver los conflictos es más rápida y presenta menos costos que un análisis constitucional de la situación. El tercero, que los casos clásicos del derecho no siempre presentan asuntos de relevancia constitucional. El cuarto, que la mayoría de las ocasiones la aplicación de los postulados constitucionales a casos específicos viene fundamentada al seguimiento de precedentes de las Altas Cortes, sobre todo de la Corte Constitucional. El quinto, el temor a la configuración de un tipo penal, para el caso, el prevaricato.

36 El primer argumento presenta serias dudas, pues la complejidad social, la descodificación del derecho, la alegación de 0 los derechos fundamentales y principios constitucionales no disminuye considerablemente en esos casos. La mayoría de los planteamientos de tutela o los clásicos conflictos de constitucionalidad de una ley han tenido de forma directa o indirecta su fuente en problemas de jueces de instancia. Luego, mal podría pensarse que en los clásicos conflictos menores no se plantean ante los jueces de instancia. No obstante, este contraargumento debe atemperarse por la concepción de que tal vez gran parte de los casos planteados no se establece en clave constitucional. 


\section{Constitucionalización legislativa}

A diferencia del proceso de constitucionalización del derecho efectuado por parte de la judicatura, el del legislador ha tenido una respuesta tardía ${ }^{37} \mathrm{y}$ ha presentado estrategias de especificación diversas ${ }^{38}$. Antes de desarrollar esta idea, es bueno hacer dos aclaraciones preliminares. La primera respecto a que la constitucionalización legislativa tiene dos vías, una directa y otra indirecta; la directa es aquella mediante la cual se efectúa el desarrollo de componentes constitucionales en el ordenamiento jurídico; la indirecta se refiere a que la importancia democrática del órgano legislativo constituye en sí misma un desarrollo constitucional; no sobra decir que en este escrito se aludirá especialmente a la primera. La segunda, que el proceso de constitucionalización legislativa puede tener una fase previa referida a la creación del derecho y otra relativa a la forma de ejecución; acá se revisará esta segunda.

Más de un decenio después de la expedición de la Constitución de 1991, la tarea del legislador se desarrolló en materia penal ${ }^{39}$, laboral ${ }^{40}$, civil $^{41}$, procesal $^{42}$, administrativa ${ }^{43}$, con la materialización directa de postulados constitucionales en las leyes. Esta ma-

37 Esta respuesta tardía puede explicarse con la dificultad del consenso, lo contradictorio de la constitucionalización política, y la necesidad de establecer pautas más estables.

38 Los más afectados con el proceso de constitucionalización del derecho son dos principios clásicos del derecho: la autodeterminación del legislador y la autonomía de la voluntad. Ello no quiere decir que principios relacionados no hayan sido afectados, sino que a manera de ejemplo en estos dos casos similares puede verse el mayor contraste. Estos principios se ven limitados y se les configura desde una óptica distinta. La autonomía de la voluntad se ve afectada por lo que se ha denominado como transacciones forzosas. Por su parte, la competencia del legislador a efectos de reglamentar sus disposiciones ha sido afectada en la figura de los márgenes de acción amplios.

39 Colombia, Ley 906 de 2004, por la cual se expide el Código de Procedimiento Penal, 45.658 Diario Oficial (1 de septiembre de 2004). Disponible en: http://www.alcaldiabogota.gov.co/ sisjur/normas/Norma1.jsp?i=14787

40 Colombia, Ley 712 de 2001, por la cual se reforma el Código Procesal del Trabajo y de la Seguridad Social, 44.640 Diario Oficial (8 de diciembre de 2001). Disponible en: http://www. secretariasenado.gov.co/senado/basedoc/codigo_procedimental_laboral.html

41 Colombia, Ley 1098 de 2006, por la cual se expide el Código de la Infancia y la Adolescencia, 46.446 Diario Oficial (8 de noviembre de 2006). Disponible en: http://www.secretariasenado. gov.co/senado/basedoc/ley_1098_2006.html

42 Colombia, Ley 1564 de 2012, por medio de la cual se expide el Código General del Proceso y se dictan otras disposiciones, 48.489 Diario Oficial (12 de julio de 2012). Disponible en: http:// www.secretariasenado.gov.co/senado/basedoc/ley_1564_2012.html

43 Colombia, Ley 1437 de 2011, por la cual se expide el Código de Procedimiento Administrativo $y$ de lo Contencioso Administrativo, 47.956 Diario Oficial (18 de enero de 2011). http://www. secretariasenado.gov.co/senado/basedoc/ley_1437_2011.html 
terialización del derecho por parte del legislador ha tenido cabida especialmente en aquellos campos en los cuales hay necesidad de proteger una parte "débil" de las distintas relaciones. Es decir, donde ha sido necesario buscar una igualdad de hecho en aras a la igualdad de derecho.

Las formas clásicas mediante las cuales la constitucionalización del derecho hace carrera utilizando como vehículo a la ley utilizan tres estrategias generales: la integración normativa, la interpretación conforme y la fundamentación ${ }^{44}$. La primera es la integración directa de los postulados constitucionales a la ley, como el artículo 21 de la Ley 734 de 2002, que establece:

En la aplicación del régimen disciplinario prevalecerán los principios rectores contenidos en esta ley y en la Constitución Política. En lo no previsto en esta ley se aplicarán los tratados internacionales sobre derechos humanos y los convenios internacionales de la OIT [Organización Internacional del Trabajo] ratificados por Colombia.

La segunda es la interpretación conforme, mediante la cual se desea que los problemas de interpretación de la ley sean resueltos de conformidad con lo dispuesto en la Constitución. La Ley 1564 de 2012 estipula:

Al interpretar la ley procesal el juez deberá tener en cuenta que el objeto de los procedimientos es la efectividad de los derechos reconocidos por la ley sustancial. Las dudas que surjan en la interpretación de las normas del presente código deberán aclararse mediante la aplicación de los principios constitucionales y generales del derecho procesal garantizando en todo caso el debido proceso, el derecho de defensa, la igualdad de las partes y los demás derechos constitucionales fundamentales. El juez se abstendrá de exigir y de cumplir formalidades innecesarias.

La tercera es la reglamentación eminentemente moral y materializada de los postulados constitucionales, que parece buscar la fundamentación de las regulaciones jurídicas, que en sus artículos singulares y como conjunto puede verse como un desarrollo de los

44 Además de estas estrategias, en múltiples formas se puede notar la constitucionalización del derecho: mediante el desarrollo de leyes estatutarias en el tema de los derechos fundamentales, la regulación de acciones constitucionales y la reinscripción de postulados constitucionales, entre otras. 
postulados constitucionales. La ley 1480 de 2011 preceptúa en el artículo 1:

Esta ley tiene como objetivos proteger, promover y garantizar la efectividad y el libre ejercicio de los derechos de los consumidores, así como amparar el respeto a su dignidad y a sus intereses económicos...

Bien sea a manera de integración, criterios hermenéuticos, normas expresas o fundamentación, puede notarse un adelanto de la constitucionalización legislativa. Aunque a los juristas que han tenido sus desarrollos jurídicos e investigativos con posterioridad a la nueva Constitución, no les parezcan importantes estas manifestaciones por resultarles superfluas, un argumento histórico ayudaría a aclarar la situación. Una revisión de la legislación existente antes de la Carta demuestra la ausencia de las estrategias antedichas en la reglamentación legal. A manera de ejemplo: en el Decreto 1400 de 1970 o Código de Procedimiento Civil, no pueden verse las alusiones transcritas en los párrafos anteriores.

Además, hay que resaltar que la tarea del legislador de desarrollar los postulados constitucionales, en las estrategias referidas, se ve garantizada por la labor de la Corte Constitucional, como se estableció en el acápite anterior.

\section{Constitucionalización práctica y académica}

La constitucionalización práctica se ve desde dos perspectivas diferentes, una sustancial y otra procesa ${ }^{45}$. La primera refiere a la utilización de alegatos constitucionales por parte del demandante o del demandado en los procesos judiciales. Cada vez es más frecuente que se acuda a posturas constitucionales para fundamentar una pretensión o tratar de eximirse de ella. A diferencia de otrora, cuando el principal argumento de litigio era una posición legal.

La perspectiva procesal refiere a que se ha mutado la forma clásica de litigar; la Constitución de 1991 ha propiciado nuevas formas de litigio ${ }^{46}$. Así pues, la acción de tutela y los alcances de la acción

45 Esta división se efectúa por categorías de acento, no por el deseo de negar las relaciones que hay entre estas nociones.

46 Juan Jacobo Calderón-Villegas, La constitucionalización del derecho privado. La verdadera historia del impacto constitucional en Colombia, Uniandes, Bogotá (2011). 
de inconstitucionalidad ante la Corte presentan retos interesantes y una nueva forma de resolver los litigios, en especial en la aplicación y protección de los principios constitucionales.

El proceso de constitucionalización en la academia ha sido interesante y de una aparentemente más fácil adaptación, pues se ha llevado a cabo preferiblemente en niveles altos de abstracción y en la especulación de situaciones jurídicas. En la academia, el proceso de constitucionalización se ha visto desde el estudio y la enseñanza, las asignaturas en los programas de pregrado y posgrado, la celebración de cursos de educación continuada y las publicaciones.

El estudio y la enseñanza del derecho variaron. No se trata de aprender de memoria fórmulas jurídicas exactas para la solución de problemas concretos. Ahora se ha hecho importante el estudio de la fundamentación del derecho sobre el dogmatismo clásico, la comprensión holística e integral de los diferentes materiales jurídicos respecto de visiones sectoriales, las competencias críticas de los estudiantes sobre el aprendizaje memorístico de fórmulas jurídicas; en síntesis, cobran importancia la teoría del derecho, la argumentación jurídica y las visiones alternas ${ }^{47}$.

El número de asignaturas que se estudian desde el punto de vista constitucional es considerable y difícilmente se conciben planes de asignaturas que no toquen de forma directa o indirecta la categoría del derecho constitucional, aunque se trate de una materia dogmática. Esto muestra la importancia que esa perspectiva ha adquirido, sobre todo, en las últimas décadas.

En los programas de posgrado, el asunto es similar. El derecho constitucional está inmerso en las asignaturas de los programas o, más importante aún, en las denominaciones de los programas. Es decir, no solamente se rastrea la importancia en las asignaturas sino que también en el país hay más de dos decenas de posgrados en derecho constitucional. Algo similar sucede con los cursos de educación continuada, seminarios y congresos: la importancia de la constitucionalización del derecho se rastrea en las temáticas, en los enfoques y en los contrastes. Los textos en los cuales se revisa el derecho constitucional también son abundantes. En ocasiones,

47 Juan Antonio Pérez-Lledó, Teoría y práctica en la enseñanza del derecho, 5 Academia. Revista sobre enseñanza del Derecho, 9, 85-189 (2007). Disponible en: http://www.derecho.uba.ar/ publicaciones/rev_academia/revistas/09/teoria-y-practica-en-la-ensenanza-del-derecho.pdf 
el fenómeno ha llevado a la necesidad de reconstruir o defender las concepciones clásicas del derecho sobre los que se fundó el ordenamiento jurídico a finales del siglo XIX.

\section{TRES VISIONES ACERCA DE CÓMO SE DEBE CONSTITUCIONALIZAR EL DERECHO}

Esta parte del artículo presenta algunas de las visiones prescriptivas acerca de cómo debe ser el proceso de constitucionalización del derecho. En última instancia, se quieren exponer algunas ideas acerca de cómo puede mejorarse el proceso que se ha venido dando. Al igual que como ocurre con las ocasiones en las cuales se prescribe algo, la existencia de visiones diversas en este punto es común. Es bueno resaltar para el caso, sin decir que sean las únicas, tres visiones diferentes acerca del proceso de constitucionalización: (1) la perspectiva idealista que subyace a los planteamientos de Ronald Dworkin acerca de la visión del derecho como integridad; (2) la perspectiva analítica representada por Robert Alexy acerca de los márgenes de acción; (3) y la visión constructiva e integradora del proceso de constitucionalización del derecho. En adelante, se examinan las tesis básicas de estas posturas, en especial, se trata de desarrollar la tercera visión, una alternativa a las concepciones más comunes.

\section{A. La visión idealista del proceso de constitucionalización}

Esta visión que nace desde la filosófica del derecho refleja un planteamiento subyacente a las tesis de Dworkin, al cual se adscribe de forma directa o indirecta ${ }^{48}$. Según esta posición, la constitucionalización del derecho ha de verse como un proceso que lleva a una concepción sinérgica del derecho constitucional y del derecho privado en la cual las dos esferas, antes delimitadas, se integran de forma armónica. De esta forma, el derecho llega a verse como un conjunto integrado en el que lo jurídicamente permitido, ordenado

48 Ronald Dworkin, Los derechos en serio, 651-101, Ariel, Barcelona (1995). Rodolfo Arango, ¿Hay respuestas correctas en el Derecho?, Siglo del Hombre Editores, Bogotá (1999). 
y prohibido por las normas constitucionales y legales se funde en una sola concepción.

Esta forma de ver el derecho está relacionada, en especial, con una postura interpretativa en la que el principal protagonista es el juez. Nadie que desee ser tomado en serio puede afirmar que las normas constitucionales y las de grado inferior dicen lo mismo. La integración del derecho se efectúa especialmente desde la interpretación, bien sea al momento de colmar antinomias o de solucionar anomias, o en el momento en que la ley presente indeterminación semántica, sintáctica, estructural o pragmática. Así pues, los postulados constitucionales se funden para prescribir una especie de respuesta correcta en todos los casos. El margen de discrecionalidad para el juez o para el legislador es casi nulo. Pues, estos en últimas efectúan un análisis del derecho en todas las posibilidades y escogen la respuesta más adecuada en la formación o aplicación del derecho.

Esta tesis ha sido defendida especialmente por la Corte Constitucional en algunas de sus sentencias y por un sector de la academia. La Corte Constitucional ha afirmado:

No es posible, entonces, interpretar una institución o un procedimiento previsto por la Constitución por fuera de los contenidos materiales plasmados en los principios y derechos fundamentales. Existe una nueva estrategia para el logro de la efectividad de los derechos fundamentales. La coherencia y la sabiduría de la interpretación y, sobre todo, la eficacia de los derechos fundamentales en la Constitución de 1991, están asegurados por la Corte Constitucional. Esta nueva relación entre derechos fundamentales y jueces significa un cambio fundamental en relación con la Constitución anterior; dicho cambio puede ser definido como una nueva estrategia encaminada al logro de la eficacia de los derechos, que consiste en otorgarle de manera prioritaria al juez, y no ya a la administración o al legislador, la responsabilidad de la eficacia de los derechos fundamentales ${ }^{49}$.

El grupo de investigación Neoconstitucionalismo y Derecho, de la Universidad Santo Tomás, Bucaramanga, liderado por Rodolfo Delgado, sostiene una tesis según la cual la constitucionalización del derecho implica una consolidación coherente del derecho posi-

49 Corte Constitucional, Sentencia T-406 de 1992, 5 de junio de 1992. Magistrado ponente Ciro Angarita-Barón. Disponible en: http://www.corteconstitucional.gov.co/relatoria/1992/t-406-92. htm 
tivo, jurisprudencial, legislado con el derecho constitucional ${ }^{50}$. La solución a todos los casos debe establecerse con base en la integración armónica de los diferentes materiales del derecho. Según se entiende, acá el acento recae no tanto en la integración sino en la ontología del derecho.

Contra estas tesis judiciales y académicas podrían aducirse diversos argumentos. Quizás los más importantes sean tres: el cognitivismo epistemológico, la relatividad ética y el ultrarracionalismo. Según la primera tesis, no está claro cómo se pueda conocer el contenido y el alcance de los valores, principios y reglas constitucionales de forma precisa; los valores y principios son una magnitud que difícilmente pueden precisarse en cuanto a sus características, lo cual haría muy difícil operar de la manera descrita. Según la segunda objeción, no podría establecerse una concepción del derecho como integridad por cuanto el establecimiento de lo que significan los valores, la forma de resolver su colisión y la relación con el derecho legislado presentaría una pluralidad de alternativas, se podría sostener casi cualquier laya de solución acudiendo a los principios. Por su parte, la tercera objeción manifiesta que estas tesis llevan a un ultrarracionalismo, en la medida en que se le exige a la razón más de lo que puede brindar en estos campos.

\section{B. E1 modelo de constitucionalización adecuado}

Esta visión acerca del proceso de constitucionalización, que tiene su origen más importante en la teoría jurídica, refiere un punto intermedio entre dos extremos nocivos. El principal representante de esta corriente es Robert Alexy. Este autor, como forma de librar los excesos nocivos de la infraconstitucionalización y la supraconstitucionalización propone lo que denomina como "constitucionalización adecuada" ${ }^{51}$.

La infraconstitucionalización consiste en un "demasiado poco" en el proceso de regulación constitucional. Desde esta óptica, la Constitución no reglamenta todos los aspectos jurídicos impor-

50 Rodolfo Delgado-Gamboa, Autonomía privada: contratos en el Estado Social de Derecho, en Memorias del $2^{\circ}$ Congreso Internacional de Derecho Empresarial y Contractual, Organización y Actividad Empresarial, 57-95, Universidad Santo Tomás, Bucaramanga, Colombia (2012).

51 Robert Alexy, Tres escritos sobre los derechos fundamentales y la teoría de los principios, 22-34, Universidad Externado de Colombia, Bogotá (2003). 
tantes que debe regular. Luego, la principal fuente de regulación jurídica vendría del legislador. Podría hablarse de un Estado eminentemente legislativo.

La posición contraria, la supraconstitucionalización, se refiere a un "demasiado mucho" en la regulación constitucional. La Constitución regula más de lo que debería regular lo que lleva a que el legislador pierda facultades en la reglamentación jurídica. "El Legislador perdería toda autonomía. Su actividad se agotaría en la mera definición de aquello que ya está decidido por la Constitución. Como consecuencia de ello, 冈el tránsito del Estado de legislación parlamentaria al Estado jurisdiccional — de la Jurisdicción Constitucional $-\triangle$ sería imparable" 52 .

La mediación de los dos modelos ${ }^{53}$, como se dijo, se lleva a efecto mediante la noción de constitucionalización adecuada. La constitucionalización adecuada del derecho lleva a que la Constitución regule aspectos importantes que debe reglamentar en la vida jurídica pero al mismo tiempo deje ciertos márgenes de acción al legislador. Principalmente, estos márgenes de acción pueden ser epistémicos o estructurales. Los márgenes de acción epistémicos se refieren a la capacidad cognitiva para reconocer lo que la Constitución permite, ordena o prohíbe. "Si se quiere afinar el planteamiento, puede decirse que el margen de acción epistémico deriva de los límites de la capacidad para reconocer los límites de la Constitución”. Estos márgenes pueden ser normativos o empíricos. Por su parte, según los márgenes de acción estructurales, el legislador es libre de obrar en aquellos casos en los cuales la Constitución no ha ordenado ni prohibido nada o en desarrollo de estas concepciones. Estos márgenes de acción pueden ser de tres clases: fijación de fines, fijación de medios y ponderación.

A esta visión normativa del proceso de constitucionalización se le pueden objetar dos cuestiones: excesivo formalismo y falta de claridad conceptual. La primera objeción manifiesta que un modelo

52 Robert Alexy, Teoría de los derechos fundamentales, 21, Centro de Estudios Políticos y Constitucionales, CEPC, Madrid (1993).

53 En la primera constelación se confiaba todo a la discrecionalidad del legislador; esto corresponde al modelo puramente procedimental. En la segunda constelación, por el contrario, no se confiaba nada a su discrecionalidad; esto es expresión del modelo puramente material de Constitución. Pues bien, la tercera constelación consiste en que se confian algunas cosas a su discrecionalidad y otras no, es decir, hay ciertas cosas que están ordenadas o prohibidas. 
de este carácter analítico deja por fuera los aspectos materiales de la Constitución. Resulta insuficiente para establecer los elementos sustanciales que permitan la consolidación del proceso de constitucionalización. La segunda objeción establece que la utilización de términos vagos y ambiguos, como "importantes" o "adecuados" no logra establecer una verdadera ayuda para los elementos que hay que constitucionalizar.

\section{El proceso de constitucionalización constructivo}

Lo que se ha denominado como proceso de constitucionalización constructivo se presenta como un punto de vista alterno al del proceso de constitucionalización adecuado e idealista. Trata, pues, de establecerse como una forma de no caer en los excesos del idealismo, de lo irrealizable, del ultrarracionalismo, ni tampoco, de lo eminentemente analítico, estructural, falto de contenido. Además, no desea poner el acento en la labor del juez ni del legislador, sino que precisa de la academia.

El proceso de constitucionalización constructivo es una noción que se define por sus caracteres esenciales: histórico-evolutivo, se construye mediante pactos; es holístico, práctico y teórico, y moderadamente racional. Pese a los rasgos que se bosquejan a continuación, esta perspectiva es una idea en maduración, mediante la cual se pretende orientar y comprender el proceso de mejor forma.

Desde esta perspectiva: la constitucionalización del derecho no plantea un modelo ideal de Estado ni de ordenamiento jurídico. No es una teoría idealista acerca de cómo debe construirse un ordenamiento ideal de tipo sistemático con teoremas, tesis, reglas de formación y transformación ${ }^{54}$, en el cual no queda margen de discrecionalidad para la toma de decisiones por parte de los operadores jurídicos. Ese tipo de construcción sistémica no se ha dado en el derecho ni se va a dar. Plantearse una visión idealista es una alternativa plausible que puede ayudar a dirigir acciones pero que constituye una quimera.

La visión que se plantea no busca bosquejar soluciones ideales o irrealizables, sino que busca la progresiva constitucionalización

54 Rupert Schreiber, Lógica del Derecho, Distribuciones Fontamara, México (1999). 
del derecho de manera creciente y constructiva. En otras palabras: no busca un modelo ideal sino constitucionalizar de forma paulatina y prudente. Se quiere decir, en primer lugar, que el proceso de constitucionalización del derecho no puede consolidarse en períodos cortos, necesita de instancias de tiempo largas para que sus elementos se puedan mejorar. Como todos los cambios fuertes, las transiciones son traumáticas. En el tema teórico y práctico, el proceso debe consolidarse dócilmente. Eso conlleva el trabajo arduo de "los juristas" en sus diferentes roles para lograr su consolidación. Se busca la progresiva constitucionalización del derecho mediante la modificación paulatina de los preceptos y conductas que no compartan la axiología constitucional.

La constitucionalización del derecho implica la necesidad de construir paulatinamente pactos jurídicos más o menos estables, mediante los cuales se otorgue sentido a las disposiciones constitucionales. Estos pactos jurídicos son acuerdos mínimos entre los diferentes actores, mediante los cuales se especifica el significado de lo jurídicamente obligatorio y permitido por las normas de derecho constitucional. Constituyen, pues, un importante contenido material de la Constitución de segundo grado. La construcción de los pactos jurídicos y sus implicaciones en las diferentes órbitas del derecho no significa que no hay criterios jurídicos diferentes a los del pacto. Los hay. Constituyen desacuerdos razonables.

La mayoría de las veces, la Corte Constitucional establece el significado de los pactos jurídicos por vía de autoridad, mediante la noción de reglas y subreglas. Y trata de hacerlos obligatorios por distintas rutas jurídicas: revisión de tutelas, acciones de inconstitucionalidad, alusiones a prevaricato, sentencias inter pares e inter comunis.

Pese al rol importante que ha ostentado la Corte Constitucional en el proceso de constitucionalización, y al papel que tiene el legislador en los ordenamientos jurídicos que se constitucionalizan por vía legislativa, en esta perspectiva, en principio, puede decirse que no se basa en un proceso guiado sino en una construcción colectiva. Este proceso constructivo desea que se trabaje de forma mancomunada por los diferentes actores, lo cual incluso se convierte en un punto de legitimidad del proceso. Es decir, la vía de la constitucionalización no es eminentemente judicial ni legislativa, 
como ocurre con las tesis idealistas o analíticas, sino que busca el trabajo mancomunado de los demás actores.

Los pactos jurídicos impuestos por la Corte no necesariamente conducen a que los demás actores queden marginados del proceso. El legislador, por ejemplo, mediante la ley de habeas data cambió las subreglas constitucionales en ese sentido. Y tampoco puede negarse el papel de respaldo que ostenta la academia en la consolidación de estos pactos.

Pese a la anterior afirmación, se establece que la academia tiene el principal punto de concurrencia y expansión del proceso. Ella es la encargada principalmente de la formación y la orientación de las soluciones de los problemas jurídicos. El proceso guiado por la academia permite una construcción más estable y a largo plazo. Es más tecnificada. Permite el control de la actividad estatal. Descarga las soluciones del juez y el legislador.

La formación construccional va a permitir la articulación teórica y práctica ${ }^{55}$. Uno de los principales problemas de la enseñanza y del derecho, para abreviar las cosas, se da porque no hay una adecuada coherencia entre los planteamientos teóricos y los prácticos. La teoría que se enseña no es útil ${ }^{56}$ y la práctica que se instruye no es realista. La academia es la llamada a que los postulados y las construcciones conceptuales respondan a la necesidades contextuales del entorno social y al perfilamiento de los roles de los juristas de forma progresiva.

La constitucionalización del derecho no implica la creación de un orden justo de formulaciones jurídicas y normas plenamente coherentes, en el cual se materialicen los postulados constitucionales y se establezcan modelos específicos de comportamiento. Lógicamente, eso sería imposible por los límites de la razón; sería hiperracionalismo. La constitucionalización del derecho pretende

55 Esta importancia de la formación académica, que valora de manera más adecuada los cambios del proceso de constitucionalización, permite afirmar, por ejemplo, que la constitucionalización implica en ocasiones la no aplicación directa de los postulados de la constitucionalización. La constitucionalización constructiva del derecho no puede verse solo desde la aplicación directa de los postulados constitucionales. El derecho privado puede constitucionalizarse con diversos canales de impregnación. Por ejemplo, en ocasiones, la aplicación nominal de la ley puede resultar en la constitucionalización del derecho ya que el legislador tiene autonomía en sus decisiones.

56 En ocasiones, es descontextualizada, pues no responde a problemas actuales y se basa en debates de otros ordenamientos jurídicos. 
acuerdos para una progresiva eliminación de la injustica y no una plena realización de la justicia.

\section{CONCLUSIONES}

El estudio del proceso de constitucionalización puede ser revisado desde diferentes enfoques: la economía, la sociología, la filosofía política y la historia, entre otros. Cada uno de estos enfoques arroja información valiosa sobre el proceso y contribuye a la articulación contextual del fenómeno. No obstante, desde una perspectiva dogmática, debe partir del establecimiento de categorías de análisis, como presupuestos epistemológicos, que permitan entender la forma en que ha venido incursionando en la práctica y la teoría jurídica local.

Así pues, la constitucionalización implica la relación entre dos dimensiones prima facie separadas jurídica e históricamente, y que han venido a juntarse en un proceso lento, complejo y contradictorio.

Por la naturaleza del fenómeno, se considera que la mejor forma de estudiarlo y perfeccionarlo debe partir de la conciencia alternativa de que se trata de un proceso que desde sus aristas idealistas y eminentemente analíticas no conduce a resultados plausibles. Por tanto, se plantea como alternativa lo que se ha denominado como el proceso de constitucionalización constructivo. Este concepto se explica mediante sus caracteres esenciales: histórico-evolutivo, se construye mediante pactos, holístico, práctico y teórico, y moderadamente racional.

Por tanto, entender la constitucionalización desde una visión histórica y constructiva no busca bosquejar soluciones ideales o irrealizables, sino constitucionalizar de forma paulatina y prudente. Se quiere decir: en primer lugar, que el proceso de constitucionalización del derecho no puede consolidarse en períodos cortos, necesita de instancias de tiempo largas para que sus elementos se puedan mejorar y, en segundo lugar, debe basarse en un conocimiento ontológico de las virtudes y consecuencias del fenómeno. 


\section{BIBLIOGRAFÍA}

\section{Libros}

Alchourrón, Carlos \& Bulygin, Eugenio, Introducción a la metodología de las ciencias jurídicas y sociales, Editorial Astrea, Buenos Aires (1974). Disponible en: http:// www.cervantesvirtual.com/nd/ark:/59851/bmczc7x4

Alexy, Robert, Teoría de los derechos fundamentales, Centro de Estudios Políticos y Constitucionales, CEPC, Madrid (1993).

Alexy, Robert, Tres escritos sobre los derechos fundamentales y la teoría de los principios, Universidad Externado de Colombia, Bogotá (2003).

Arango, Rodolfo, ¿Hay respuestas correctas en el Derecho?, Siglo del Hombre Editores, Bogotá (1999).

Bernal, Carlos, Elneoconstitucionalismo a debate, Universidad Externado de Colombia, Bogotá (2006).

Bernal, CARLos, El neoconstitucionalismo y la normatividad en el derecho, Universidad Externado de Colombia, Bogotá (2009).

Calderón-Villegas, Juan Jacobo, La constitucionalización del derecho privado. La verdadera historia del impacto constitucional en Colombia, Uniandes, Bogotá (2011).

Carbonell, Miguel, Tendencias del constitucionalismo en Iberoamérica, Seminario Internacional Nuevas tendencias del constitucionalismo en América Latina, Universidad Nacional Autónoma de México, UNAM, Instituto de Investigaciones Jurídicas, México (2009). Disponible en: http://www.idea. int/publications/tendencies_of_constitutionalism/upload/Tendencias-delconstitucionalismo-en-Iberoam $\% \mathrm{C} 3 \% \mathrm{~A} 9$ rica_inlay.pdf

Carbonell, Miguel, Teoría del neoconstitucionalismo, ensayos escogidos, Trotta, Universidad Nacional Autónoma de México, UNAM, Instituto de Investigaciones Jurídicas, Madrid (2007).

Carbonell, Miguel \& García-Jaramillo, Leonardo, eds., El canon neoconstitucional, Universidad Externado de Colombia, Bogotá (2010).

Delgado-Gamboa, Rodolfo, Autonomía privada: contratos en el Estado Social de Derecho, en Memorias del $2^{\circ}$ Congreso Internacional de Derecho Empresarial y Contractual, Organización y Actividad Empresarial, Universidad Santo Tomás, Bucaramanga, Colombia (2012).

Dworkin, Ronald, Los derechos en serio, Ariel, Barcelona (1995).

Elster, Jon \& Slagstad, Rune, Constitucionalismo y democracia, Fondo de Cultura Económica, FCE, Colegio Nacional de Ciencias Políticas y Administración Pública, México (2001).

Ferrajoli, Luigi, Derecho y razón, Trotta, Madrid (2001).

Gargarella, Roberto \& Courtis, Christian, El nuevo constitucionalismo latinoamericano: promesas e interrogantes, Serie Políticas Sociales, 153, Comisión 
Económica para América Latina y el Caribe, CEPAL, Santiago de Chile (2009). Disponible en: http://www.cepal.org/publicaciones/xml/2/37882/sps153-ddsconstitucionalismo.pdf

Julio-Estrada, Alexei, La eficacia de los derechos fundamentales entre particulares, Universidad Externado de Colombia, Bogotá (2002).

LóPez-Medina, Diego, Interpretación constitucional, Universidad Nacional de Colombia, Bogotá (2006).

López-Medina, Diego, Teoría impura del derecho. La transformación de la cultura jurídica latinoamericana, Legis, Universidad de los Andes, Universidad Nacional, Bogotá (2004).

Lorenzetti, Ricardo, Tratado de los contratos, parte general, Rubinzal-Culzoni, Buenos Aires (2004).

Schreiber, Rupert, Lógica del Derecho, Distribuciones Fontamara, México (1999).

\section{Contribuciones en obras colectivas}

Fajardo-Glauser, Silvia Tutela de derechos fundamentales en otros capitulos, en Teoría constitucional y políticas públicas: bases críticas para una discusión, MANUEL JosÉ Cepeda-Espinosa, Eduardo Montealegre-Lynett \& Alexei Julio-Estrada, Universidad Externado de Colombia, Bogotá (2007).

\section{Revistas}

Atienza, Manuel, El futuro de la dogmática jurídica, crítica de libros, 10 El Basilisco, 63-69 (1980). Disponible en: http://www.fgbueno.es/bas/pdf/bas11008.pdf

Comanducci, Paolo, Formas de (neo)constitucionalismo: un análisis metateórico, 16 Isonomía, 89-112 (2002). Disponible en: http://www.upf.edu/filosofiadeldret/_pdf/ comanducci-formas.pdf

García-Villegas, Mauricio, Constitucionalismo aspiracional: Derecho, democracia y cambio social en América Latina, 25 Análisis Político, 75, 89-110 (mayo-agosto, 2012). Disponible en: http://www.scielo.org.co/scielo.php?script=sci_arttext\&p id $=$ S0121-47052012000200005

García-Villegas, Mauricio, Notas preliminares para la caracterización del derecho en América Latina, 26 Revista El Otro Derecho, 13-49 (2003). Disponible en: http:// www.oas.org/juridico/spanish/mauricio_garc\%C3\%ADa_villegas.htm

Pérez-Lledó, JuAn Antonio, Teoría y práctica en la enseñanza del derecho, 5 Academia. Revista sobre enseñanza del Derecho, 9, 85-189 (2007). Disponible en: http://www. derecho.uba.ar/publicaciones/rev_academia/revistas/09/teoria-y-practica-en-laensenanza-del-derecho.pdf 


\section{Documentos, ensayos}

Melero-Alonso, Eduardo, La dogmática jurídica es política. La importancia de las concepciones politicas en el trabajo de los juristas: un acercamiento desde el derecho público, Universidad Autónoma de Madrid, Madrid (2002). Disponible en: http:// www.uam.es/personal_pdi/derecho/jarsey/3publicaciones/dogmaticaespolitica. pdf

\section{Normatividad internacional}

Alemania, Grundgesetz für die Bundesrepublik Deutschland (1949). Texto en alemán: http://www.gesetze-im-internet.de/gg/BJNR000010949.html, texto en español: http://ocw.um.es/cc.-juridicas/derecho-internacional-publico-1/ejerciciosproyectos-y-casos-1/capitulo4/documento-20-constitucion-de-alemania.pdf

Argentina, Constitución Nacional (1994). Disponible en: http://www.senado.gov.ar/ deInteres

Bolivia, Constitución Politica del Estado (1995). Disponible en: http://www.lexivox.org/ norms/BO-CPE-19950206.xhtml

Bolivia, Constitución Politica del Estado (2009). Disponible en: http://bolivia.infoleyes. com/shownorm.php?id=469

Brasil, Constituição da República Federativa do Brasil (1988). Texto en portugués: http:// www.planalto.gov.br/ccivil_03/constituicao/constituicao.htm, texto en español: http://www.wipo.int/wipolex/es/text.jsp?file_id=218272

Ecuador, Constitución Politica de la República del Ecuador (1998). Disponible en: http:// www.ecuanex.net.ec/constitucion/indice.html

España, Constitución Española (1978). Disponible en: http://www.congreso.es/consti/ constitucion/indice/

Italia, Constituzione della Repubblica Italiana (1947). Texto en italiano: http://www. governo.it/Governo/Costituzione/principi.html, texto en español: http://www. italianoinfamiglia.it/documenti/costituzione-in-spagnolo.pdf

Panamá, Constitución Política de la República de Panamá (1972). Disponible en: http:// www.asamblea.gob.pa/main/LinkClick.aspx?fileticket=fDgmRvYW8cY\%3D \&tabid $=123$

Perú, Constitución Política del Perú (1993). Disponible en: http://www.tc.gob.pe/ constitucion.pdf

Portugal, Constitução da República Portuguesa (1976). Texto en portugués: http://www. parlamento.pt/legislacao/paginas/constituicaorepublicaportuguesa.aspx, texto en español: http://www.viajeuniversal.com/portugal/constitucionl.htm, http:// www.viajeuniversal.com/portugal/constitucion2.htm

Venezuela, Constitución de la República Bolivariana de Venezuela (1999). Disponible en: http://www.tsj.gov.ve/legislacion/constitucion1999.htm 


\section{Normatividad nacional}

Colombia, Constitución Política de la República de Colombia (1886). Disponible en: http:// www.alcaldiabogota.gov.co/sisjur/normas/Norma1.jsp?i=7153

Colombia, Constitución Política (1991). Disponible en: http://www.alcaldiabogota.gov. co/sisjur/normas/Norma1.jsp?i=4125

Colombia, Decreto 1400 de 1970, por el cual se expide el Código de Procedimiento Civil, 33.150 Diario Oficial (21 de septiembre de 1970). Disponible en: http://www. alcaldiabogota.gov.co/sisjur/normas/Norma1.jsp?i=6923

Colombia, Decreto 2591 de 1991, por el cual se reglamenta la acción de tutela consagrada en el artículo 86 de la Constitución Política, 40.165 Diario Oficial (19 de noviembre de 1991). Disponible en: http://www.alcaldiabogota.gov.co/sisjur/normas/Norma1. jsp?i=5304

Colombia, Ley 712 de 2001, por la cual se reforma el Código Procesal del Trabajo y de la Seguridad Social, 44.640 Diario Oficial (8 de diciembre de 2001). Disponible en: http://www.secretariasenado.gov.co/senado/basedoc/codigo_procedimental_ laboral.html

Colombia, Ley 734 de 2002, por la cual se expide el Código Disciplinario Único, 44.708 Diario Oficial (13 de febrero de 2002). Disponible en: http://www.secretariasenado. gov.co/senado/basedoc/ley_0734_2002.html

Colombia, Ley 906 de 2004, por la cual se expide el Código de Procedimiento Penal, 45.658 Diario Oficial (1 de septiembre de 2004). Disponible en: http://www. alcaldiabogota.gov.co/sisjur/normas/Norma1.jsp?i=14787

Colombia, Ley 1098 de 2006, por la cual se expide el Código de la Infancia y la Adolescencia, 46.446 Diario Oficial (8 de noviembre de 2006). Disponible en: http://www.secretariasenado.gov.co/senado/basedoc/ley_1098_2006.html

Colombia, Ley 1437 de 2011, por la cual se expide el Código de Procedimiento Administrativo $y$ de lo Contencioso Administrativo, 47.956 Diario Oficial (18 de enero de 2011). http://www.secretariasenado.gov.co/senado/basedoc/ley_1437_2011.html

Colombia, Ley 1480 de 2011, por medio de la cual se expide el Estatuto del Consumidor y se dictan otras disposiciones, 48.220 Diario Oficial (12 de octubre de 2011). http:// www.secretariasenado.gov.co/senado/basedoc/ley_1480_2011.html

Colombia, Ley 1564 de 2012, por medio de la cual se expide el Código General del Proceso y se dictan otras disposiciones, 48.489 Diario Oficial (12 de julio de 2012). Disponible en: http://www.secretariasenado.gov.co/senado/basedoc/ley_1564_2012.html

\section{Jurisprudencia nacional}

Consejo de Estado, Sala de lo Contencioso Administrativo, Sección Tercera, Sentencia del 13 de abril de 2011. Proceso 20480. Consejero ponente Jaime Orlando Santofimio-Gamboa. Disponible en: http://www.alcaldiabogota.gov.co/sisjur/ normas/Norma1.jsp?i=46494

Corte Constitucional de Colombia. Auto-071 de 2001, 27 de febrero de 2001. 
Magistrado ponente Manuel José Cepeda-Espinosa. Disponible en: http://www. corteconstitucional.gov.co/relatoria/autos/2001/a071-01.htm

Corte Constitucional, Sentencia C-225 de 1995, 18 de mayo de 1995. Magistrado ponente Alejandro Martínez-Caballero. Disponible en: http://www.corteconstitucional. gov.co/relatoria/1995/c-225-95.htm

Corte Constitucional, Sentencia C-037 de 1996, 5 de febrero de 1996. Magistrado ponente Vladimiro Naranjo-Mesa. http://www.corteconstitucional.gov.co/ relatoria/1996/C-037-96.htm

Corte Constitucional, Sentencia C-582 de 1999, 11 de agosto de 1999. Magistrado ponente Alejandro Martínez-Caballero. Disponible en: http://www.corteconstitucional. gov.co/relatoria/1999/C-582-99.htm

Corte Constitucional, Sentencia C-093 de 2001, 31 de enero de 2001. Magistrado ponente Alejandro Martínez-Caballero. Disponible en: http://www.corteconstitucional. gov.co/relatoria/1999/C-582-99.htm

Corte Constitucional, Sentencia C-820 de 2006, 4 de octubre de 2006. Magistrado ponente Marco Monroy-Cabra. Disponible en: http://www.corteconstitucional. gov.co/relatoria/2006/C-826-06.htm

Corte Constitucional, Sentencia T-406 de 1992, 5 de junio de 1992. Magistrado ponente Ciro Angarita-Barón. Disponible en: http://www.corteconstitucional.gov.co/ relatoria/1992/t-406-92.htm

Corte Constitucional, Sentencia T-881 de 2002, 17 de octubre de 2002. Magistrado ponente Eduardo Montealegre-Lynett. Disponible en: http://www.corteconstitucional. gov.co/relatoria/2002/t-881-02.htm

Corte Constitucional, Sentencia T-719 de 2003, 20 de agosto de 2003. Magistrado ponente Manuel José Cepeda-Espinosa. Disponible en: http://www.corteconstitucional. gov.co/relatoria/2003/T-719-03.htm

Corte Constitucional, Sentencia T-301 de 2004, 25 de marzo de 2004. Magistrado ponente Eduardo Montealegre-Lynett. Disponible en: http://www.corteconstitucional. gov.co/relatoria/2004/t-301-04.htm

Corte Constitucional, Sentencia T-340 de 2010, 11 de mayo de 2010. Magistrado ponente Juan Carlos Henao-Pérez. Disponible en: http://www.corteconstitucional.gov. co/relatoria/2010/T-340-10.htm

Corte Constitucional, Sentencia T-555 de 2011, 8 de junio de 2011. Magistrado ponente Nilson Pinilla-Pinilla. Disponible en: http://www.corteconstitucional.gov.co/ relatoria/2011/T-555-11.htm

Corte Suprema de Justicia, Sala de Casación Penal, Sentencia del 1 de agosto de 2007. Proceso 27283. Magistrado ponente Yesid Ramírez-Bastidas. Disponible en: http://beneficiosjudiciales.blogspot.com/2007/11/defensa-tecnica.html 
